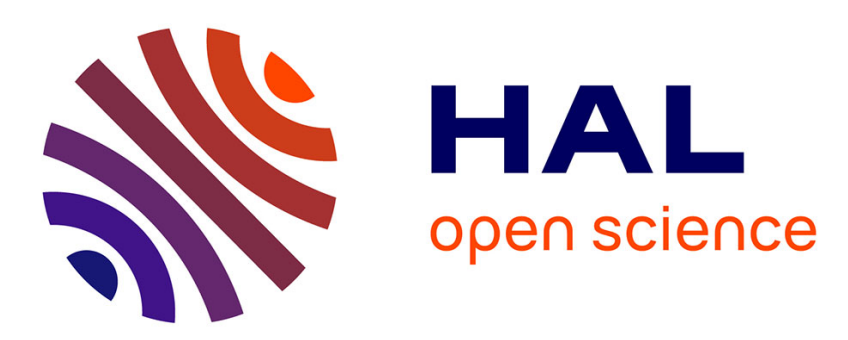

\title{
Hydrodynamic aspect of hydrothermal synthesis of quartz bulk flow regimes
}

B. Roux, O. Louchart, O. Terhmina

\section{To cite this version:}

B. Roux, O. Louchart, O. Terhmina. Hydrodynamic aspect of hydrothermal synthesis of quartz bulk flow regimes. Journal de Physique IV Proceedings, 1994, 04 (C2), pp.C2-3-C2-11. 10.1051/jp4:1994201 . jpa-00252469

\section{HAL Id: jpa-00252469 https://hal.science/jpa-00252469}

Submitted on 1 Jan 1994

HAL is a multi-disciplinary open access archive for the deposit and dissemination of scientific research documents, whether they are published or not. The documents may come from teaching and research institutions in France or abroad, or from public or private research centers.
L'archive ouverte pluridisciplinaire HAL, est destinée au dépôt et à la diffusion de documents scientifiques de niveau recherche, publiés ou non, émanant des établissements d'enseignement et de recherche français ou étrangers, des laboratoires publics ou privés. 


\title{
Hydrodynamic aspect of hydrothermal synthesis of quartz bulk flow regimes
}

\author{
B. ROUX, O. LOUCHART and O. TERHMINA \\ Institut de Mécanique des Fluides de Marseille, UMR-34 du CNRS, France
}

\begin{abstract}
In crystal growth autoclaves, dissolution zone and cristallisation zone are connected through a diaphragm. The flow regimes in such a configuration are quite complex, as they result from two buoyancy mechanisms, solutal and thermal, acting in opposite directions. In addition, the autoclave walls are thick and heat transfer in it strongly affect heat transfer in the bulk (conjugate problem).
\end{abstract}

Several model with increasing difficulties have been numerically tested to calculate the bulk flow. For a thermal boundary condition with a flux imposed at the external wall, the temperature distribution along the internal wall is found to be almost linear.

For "thermosiphon" configuration, the axisymmetric solution is completely different, but still the flow goes up along the internal wall inside the two zones. For three-dimensional solutions, the flow is going up along the axis in the crystallisation zone; showing that the axisymmetric solution is not realistic.

In addition, the stability theory indicates that after a certain threshold, the solution would become anti-symmetric and thus will be three-dimensional too.

\section{INTRODUCTION}

It is still important to optimize growth conditions of piezo-electric crystals of high quality by hydrothermal synthesis. This quality determines the performance of technological systems like resonators and oscillators which have to operate in a frequency range of $1-100 \mathrm{Mhz}$.

The quality depends on:

- chemical impurities, e.g. OH distribution (which influence surtension coefficient and chemical aging of resonators)

- crystal defects: dislocations, etching channels, fractures, etc ...(which influence the acoustic distribution).

- inclusions (iron, sodium, acmite, ...).

To determine the growth conditions for better quality we have to consider species diffusion and convection problem in the aqueous solution $\left(\mathrm{NaOH}-\mathrm{H}_{2} \mathrm{O}+\mathrm{SiO}_{2}+\right.$ mineralizing additives + impurities) in the bulk flow, and the segregation problem in the vicinity of the growing crystal.

Another important point is the reproducibility of the growth process, which means in general to consider the hydrodynamical stability of the bulk flow. 
A lot of papers have been devoted to the hydrodynamic aspects of the hydrothermal synthesis of monocrystals. In particular, we can mention Chernov book [1], a review paper by Laudise [2], several other papers by Russian specialists [3-8], and a paper by Passaret \& Regreny [9] who introduced industrial hydrothermal synthesis of quartz in France.

One of our main goal is to concentrate our effort on the bulk flow problem, and to analyze flow regimes and internal temperature gradient, $\Delta \mathrm{T}_{\text {int }}$, in crystallization zone, for at least two situations: (a) time-dependent regime $(\approx 30-40 \mathrm{~h})$ and $(\mathrm{b})$ permanent regime.

To reach this goal we seek for models and methods able to give (a) characteristics of bulk flow regimes by direct simulation and (b) hydrodynamic stability limit.

The new features now in the domain of numerical modelisation is the increase of supercomputer power, mainly through high performance distributed-memory parallel processors computers, which allow to handle more sophisticated (and more realistic) calculations than in the past. We will see that this is crucial.

\section{MAIN HYDRODYNAMIC AND THERMAL FEATURES and species distribution in autoclaves $\left(\mathrm{NaOH}-\mathrm{H}_{2} \mathrm{O}+\mathrm{SiO}_{2}\right.$ mixture)}

2.1 A schematic description of an autoclave for hydrothermal synthesis of quartz is given in Fig.1. The main teatures considered in the present paper are the following:

(a) Autoclave walls are thick. So, heat transfer in it strongly affects heat transfer in the bulk (conjugate problem).

(b) Dissolution and crystallization zones are connected through a diaphragm, which limits thermal and solutal interactions between dissolution and crystallization zones. Holes position and permeability rate (few $\%$ ) of this diaphragm are important parameters too.

(c) Two buoyancy mechanisms, solutal and thermal, act in opposite directions and lead to complex flow regimes (often three-dimensional and time-dependent).

\subsection{Basic principles}

The solution is highly concentrated in $\mathrm{SiO}_{2}$ in heated lower zone (dissolution), giving rise to a vertical, stabilizing, concentration gradient.

Simultaneously, a vertical temperature gradient $\Delta T$ ext is applied at the external part of the autoclave, which gives rise to an internal temperature gradient, $\Delta T_{i n t}$, destabilizing. The flow and growth rate increase with $\Delta T_{\text {int }}$, but $\Delta T_{\text {int }}$ does not monotonically increase with $\Delta T_{\text {ext }}$. A motion is generated which tends to reduce $\Delta \mathrm{T}_{\text {int }}$. In addition, a time-dependent phenomena occurs in industrial autoclaves which can destroy $\Delta \mathrm{T}_{\mathrm{int}}[10]$. This mechanism could give rise to a undesirable (too strong) attack of the crystal seed, before the beginning of growth. In our opinion, the phenomena observed in [10] could be due to a boiling process after a period where the solution expands with the temperature increase (the autoclave being partially filled at the beginning: $\approx 80-85 \%$ ). A similar boiling process has been reported by Popolitov et al. [7], for a laboratory autoclave with a transparent wall. But this similarity and the existence of an intermediate boiling regime in industrial autoclave [10] has not been proved yet.

Also, radial temperature gradients play a substantial role on the convective motions generated in autoclaves. They will be taken into account in our models. 
Finally, we can note that temperature and species fields are in general strongly depending on the bulk flow intensity (mainly for high Rayleigh number values which prevail in real applications). The relevant parameters for this coupling are the Prandtl and Schmidt numbers. For hydrothermal synthesis of quartz they are approximately of $\mathrm{Pr}=1$ and $\mathrm{Sc} \approx 100$. The high value of $\mathrm{Sc}$ means that species fields will be mainly affected by the convective transport, and not by diffusion.

\subsection{Specific additional difficulties (not considered here)}

In fact, the media in the dissolution zone is like a porous media at the beginning of growth process. Similarly, the crystallization zone has to be seen as a porous media, with a porosity which is time dependent. But in general, this porosity is expected to exert a damping effect and lead to a strongly reduced velocity. So, in some sense, the computation of the bulk flow without porous media gives a upper limit for the convection strength.

In addition, we would have to consider the effect of mineralizing additives ( $\mathrm{LiF} ; \mathrm{LiOH} ; \mathrm{Li}_{2} \mathrm{CO}_{2}$ ). Probably these additives would have only slight influence on the bulk flow, but they could have some influence on the crystallization process itself (which is beyond the scope of the present study).

\section{PRESENT WORK}

The present work concerns bulk flow calculations only, i.e. without phase change at crystal walls (which requires an accurate description of concentration field near the crystals).

\footnotetext{
Several models with increasing difficulties have been numerically tested

- thermal convection; single enclosure; axisymmetric model

- thermal \& solutal convection; single enclosure; axisymmetric model

- conjugate problem (conduction in wall \& convection in bulk, coupled)

- thermal convection; two connected enclosures (with diaphragm); axisymmetric model

- conjugate problem; two connected enclosures (with diaphragm); axisymmetric model

- three-dimensional model; thermal convection; two connected enclosures (with diaphragm).
}

The models consist in Navier-Stokes equations (in quasi-incompressible form, namely with Boussinesq approximation), coupled with energy (and species) conservation equations.

Two kinds of thermal boundary conditions can be used (see Fig. 2 a and b). The first corresponds to imposed flux at the external part of the autoclave wall (Fig.2a); it will be appropriate during the starting regime. The second one corresponds to imposed temperature (Fig.2b); for this case, the temperature can be given along the internal walls and we select a "thermosiphon" configuration for which the walls are isothermal (with different temperatures) in the two zones : $T_{W}=T_{1}$ for lower (dissolution) zone and $\mathrm{T}_{\mathrm{W}}=\mathrm{T}_{2}$ for the upper (crystallization) zone, with $\mathrm{T}_{1}>\mathrm{T}_{2}$.

The computations have been made with Nekton package [11], based on spectral element technique developed by Patera [12]. We used a powerful parallelized version of Nekton code developed by Fischer [13].

This numerical study permitted to identify flow behaviours for different conditions.

\subsection{Conjugate problem for an axisymmetric solution in a single enclosure}

We consider the coupling between conduction in the autoclave wall and convection in bulk, in the case of imposed llux at the external wall (Fig.2a). The results show that the temperature distribution is almost linear along the internal wall. The isotherm patterns, for a single enclosure (without diaphragm) are shown in (Figs. 3 a and $b$ ), for two values of Rayleigh number, $\mathrm{Ra}=100$ and $\mathrm{Ra}=$ 60000 , respectively, where 


$$
\mathrm{Ra}=g \alpha \Delta \mathrm{T} \text { cxt } \mathrm{R}^{3} / \nu \kappa,
$$

$\mathrm{g}$ being gravity acceleration, $\alpha$ thermal expansion coefficient, $\mathrm{R}$ internal radius of autoclave, $v$ kinematic viscosity and $\kappa$ thermal diffusivity.

We observe in Fig.3a, for $\mathrm{Ra}=100$, that the isotherms after a short distance in the wall become horizontal and regularly spaced along the vertical wall, giving a temperature distribution along the internal wall which is almost linear in $\mathrm{z}$ direction. For $\mathrm{Ra}=60000$, the isotherms distribution in the autoclave wall is about the same, but we can see a strong deformation of isotherms which are pressed down, in the bulk, to the cavity bottom (revealing a flow going down along the axis).

3.2. Effect of thermal boundary conditions for an axisymmetric solution for two enclosures separated by a diaphragm

Here we consider the case of two enclosures separated by a diaphragm. We analyze the influence of boundary thermal conditions. To simulate a boundary condition of tlux type, we simply use a linear temperature distribution (according to the results shown in \$.3.1). While for thermosiphon configuration with impose the temperature as in Fig. $2 \mathrm{~b}$.

One example of such results is given for a diaphragm of porosity $20 \%$ (of course, this porosity is extremely large compared to real autoclave; but this increases the coupling between the two zones. The results about streamlines and isotherms distributions, for Ra $=5000$ are given in Fig.4 and 5, respectively.

The two kinds of boundary conditions lead to quite different flows and temperature fields. But in the two cases, the bulk flow goes up along the internal wall, in the lower and in the upper zones, and goes down along the axis.

\subsection{Three-dimensional solution (thermosiphon type condition).}

Previous descriptions of complex fields in the case of thermosiphon configurations have been reported in several works [14-16], all showing a three-dimensional character of the flow. So, computations have been made for a three-dimensional model. But, due to limitation capability of our computer at that time (1991), we imposed a periodicity condition which allow us to reduce the computation domain to a quarter of the cylinder. Also for the sake of simplicity we consider a cylinder with a square basis instead of a circular one.

Several cases have been studied. We only present the results for $\mathrm{Ra}=5000$ in the case without diaphragm (Fig.6a and 6b), and for $\mathrm{Ra}=20000$ in the case with a diaphragm of porosity $20 \%$ (Fig. $7 \mathrm{a}$ and $7 \mathrm{~b}$ ). The fields of velocity vector clearly shows that the flow is very complex and goes up along the axis in the upper zone (which corresponds to crystallisation zone) in both cases, i.e. without diaphragm (Fig.6a) or with diaphragm (Fig.7a). This means that the axisymmetric solution shown in Fig.4a is not realistic.

Concerning the isotherm fields, we observe that for increasing $\mathrm{Ra}$, the vertical temperature gradient which is maximum at the wall, strongly decreases when appreaching the center line. We can easily anticipated that when increasing $\mathrm{Ra}$ again, a large part of the core autoclave will be almost isothermal.

Of course, these three-dimensional features would have to be controled hy a full three-dimensional calculation, which is possible now. 
For imposed heat flux conditions (with linear temperature distribution along internal wall), the relevance (or not) ol the axisymmetric model has not been yet controled.

\section{Hydrodynamical Stability of the bulk flow}

Stability theory [17] for infinite layer subject to stabilizing vertical concentration gradient and destabilizing vertical temperature gradient indicates that after a certain threshold (in terms of Rayleigh number) the fluid is no longer steady. The most unstable perturbations are time-dependent and antisymmetric (i.e., with the form $\cos \phi$, where $\phi$ is the azimuth angle. The flow just after the threshold would be three-dimensional and oscillatory.

This result has been generalized by Henry \& Roux [18] for confined cylindrical cavity, where the two opposing buoyancy mechanisms (solutal and thermal) result from thermodiffusion (Soret) effect. From the results presented in [18], which are valid for a long vertical cavity (with large aspect ratio $\mathrm{A}$ $=$ Length / Radius), we can say that the critical Rayleigh value for the onset of oscillatory regime is proportional to A :

$$
\mathrm{Ra}_{\mathrm{c}}^{\mathrm{OSC}} \approx 150-400 \mathrm{~A} \quad \text { (for our applications, } \mathrm{A}=\mathrm{L} / \mathrm{R} \approx 20-30 \text { ) }
$$

The proportionality coeflicient depends on the nature of thermal boundary conditions (from insulating to perfectly conducting walls).

New specific techniques are now developed for stability analysis, namely the continuation techniques, based on stability of numerical solutions. This powerfull approach has not been yet used for the problem discussed herein, but for zone (or half-zone) directional solidification method [19].

\section{CONCLUSIONS}

Modelling of flow regimes and heat/mass transfer in autoclave is a very difficult task, even when the problem is limited to bulk flow only. The flow regimes are very complex and depend on a lot of parameters

Axisymmetric approach can lead to completely wrong solution. Fully three-dimensional approach is generally needed for realistic descriptions of flows.

Modern parallel computing (in particular with high performance distributed-memory parallel processors) allow to handle such complex three-dimensional models, with an acceptable cost.

Improvement of the bulk modelling can be made due to power increase of parallel computers. Fully three-dimensional approach including thermal and solutal convections; two enclosures connected through a diaphragm, and conjugate problem could be undertaken.

Bulk flow modelling with porous media would be interesting to consider too, with Darcy equations for example. One the difticulty will be to get accurate physical properties of the porous media, which has to be considered as non-isotropic (and changing at the different steps of growth), in the crystallization zone, due to the elongated form of the growing crystals.

The final improvement would be to consider concentration layer calculation in the vicinity of the growing crystal.

But we recommend to consider the calculation of the bulk flow, and the calculation of concentration surrounding the growing crystal as two separate problems. Full coupling would involve too many parameters and too many different scales. 
We also strongly recommend to develop international cooperation with Russian specialists, for joint research and even for joint development for autoclave optimization and building.

Acknowledgments. The authors wish to thank the "Direction des Recherches, Etudes et Techniques" for financial support under the contract DRET $n^{\circ} 90.149$, Prof. Anthony Patera (MIT) who helped us to enter in parallel computing, Prof. Paul Fischer (Brown University) for kindly installing a Parallel version of Nekton code on our iPSC/860 computer, and the staff of Centre Ressource Informatique Spécialisé of Aix-Marseille University for his helpful assistance.

\section{REFERENCES}

[1] Chernov A.A. , Modern Crystallography. Vol. III - Crystal Growth. Chap; 9. Growth from solutions, (1984) pp. 353-414. Springer Series in Solid-State Sciences. Vol. 36.

[2] Laudise R.A., Hydrothermal synthesis of crystals. Special report, C\&EN, American Soc., Sept. 28, (1987) pp.30-43.

[3] Chernov A.A. \& Khadzhi V.E., Trapping of colloidal inclusions in the growth of quartz crystals. J. Crystal Growth, Vol. 34 (1968), pp. 641-646.

[4] Chernov A.A.\& Kuznetsov V.A. Soviet Phys. Crystallography. Vol. 14 (1970), pp. 753-756.

[5] Kuznetsov V.A. \& Lobachev A.N. Hydrothermal method for the growth of crystals. Soviet Phys. Crystallography. Vol. 17 (1973), pp. 775-804.

[6] Popolitov V.I., Shapiro A. Ya. \& Lobachev A.N.

Solubility and crystallization kinetics of tellurium dioxide in hydrothermal conditions. Soviet Phys. Crystallography. Vol. 27 (1982), pp. 225-235.

[7] Popolitov V.I.\& Shapiro A. Ya., Hydrothermal growth of single crystals of $\mathrm{TeO}_{2}$ and $\mathrm{Te}_{6} \mathrm{O}_{11} \mathrm{Cl}_{2}$ in the $\mathrm{TeO}_{2}-\mathrm{HCl}-\mathrm{H}_{2} \mathrm{O}$ system.

Soviet Phys. Crystallography. Vol. 28 (1983) pp. 220-223.

[8] Klipov V.A.\& Shamov N.N., Influence of convective flows on the growth of synthetic quartz crystals. 45th Annual. Symp. on Frequency Control. Los-Angeles(USA), (1991), 8 pages.

[9] Passaret \& Regreny A., Quelques aspects chimiques sur la solubilité et la croissance hydrothermale du quartz. CNET - Note Technique CPM / PMT / 10 (1972).

[10] SICN (1991); private communication.

[11] Nekton User's guide, version 2.8 ( juillet 1991).

[12] Patera A., A spectral element method for fluid dynamics. J. Computational Physics, Vol. 54 (1984), pp. 468-488.

[13] Fischer P.F., Spectral element solution of the Navier-Stokes equations on High performance Distributed-memory Parallel Processors, PhD Thesis MIT (june 1989). 
[14] Japkise D., Jallouk P.A. \& Winter E.R.F., Single-phase transport processes in the closed thermosiphon. Int. J. heat Mass Transfer, Vol. 14 (1971) pp. 4869-4887.

[15] Mallinson G.D., Graham A.D. \& de Vahl Davis G., Three-dimensional flow in closed thermosiphon .J. Fluid Mechanics, Vol. 109 (1973), pp. 259-275.

[16] Simon B., Hydrothermal crystallization of sodium chlorate.

J. Crystall Growth. Vol. 23 (1983), pp. 225-228.

[17] Schechter R.S., Velarde M.G. \& Platten J.K., The two-component Bénard problem. Advances in Chemical Physics, Vol. 26 (1974), pp. 267-301.

[18] Henry D. \& Roux B. , Stationary and oscillatory instabilities for mixtures subjected to Soret effect in vertical cylinder with axial temperature gradient. Proc. 4 h European Symp. on Material Sciences under Microgravity, ESA-SP-191 (1983), pp. 145-152.

[19] Chen G., Convection thermocapillaire en microgravite: aspect hydrodynamique de l'élaboration de semi-conducteurs par zone flottante. $\mathrm{PhD}$ thesis Marseille (1991).

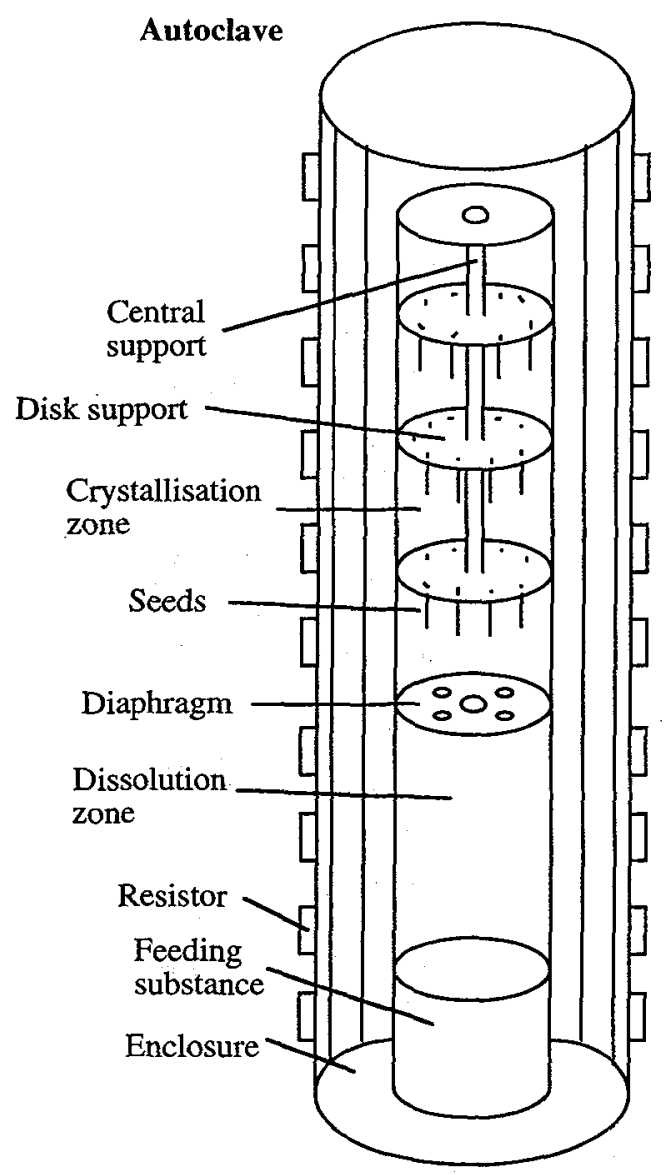

Fig.1 Autoclave Description

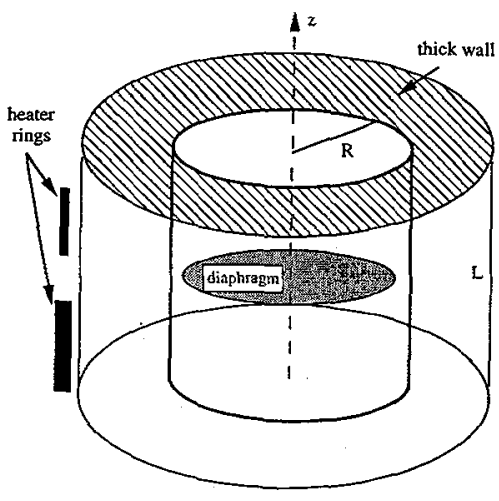

(a) imposed flux at external wall

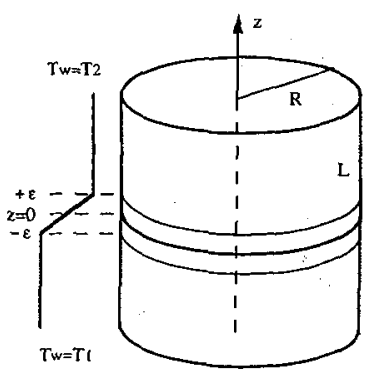

(b) thermosiphon

Fig.2 Thermal boundary conditions (a) imposed flux at external wall (b) thermosiphon 

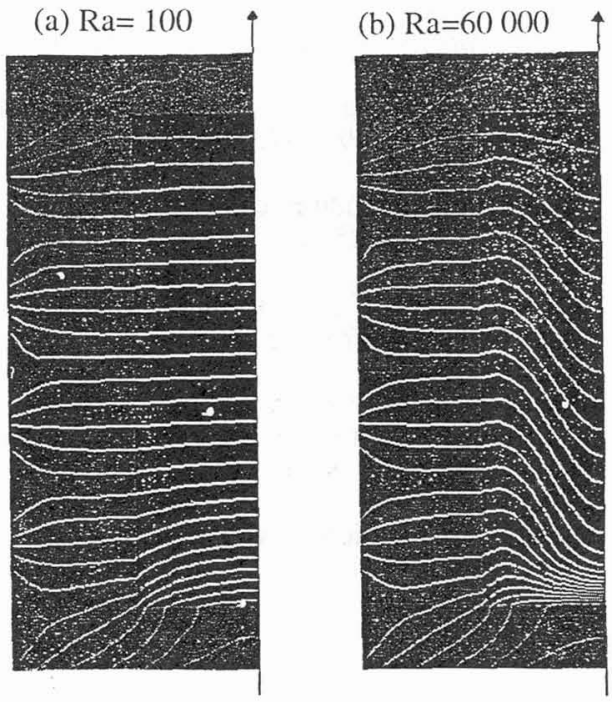

Fig.3 Conjugate problem for a single enclosure; isotherms (a) $\mathrm{Ra}=100$; (b) $\mathrm{Ra}=60000$.

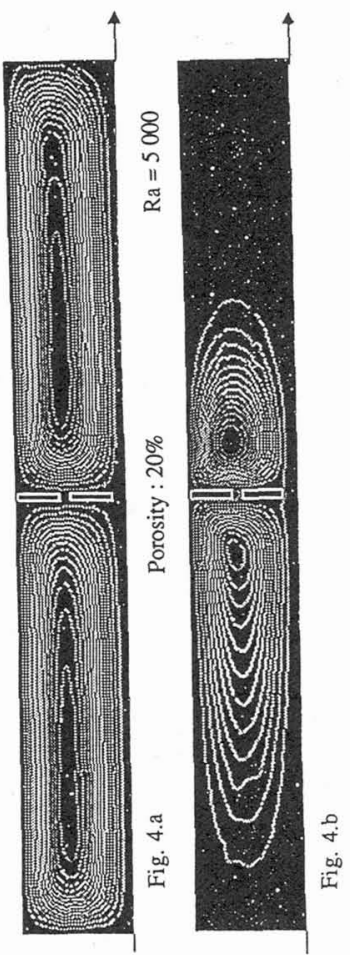

$(\mathrm{Ra}=5000 ; \mathrm{Pr}=5.4)$

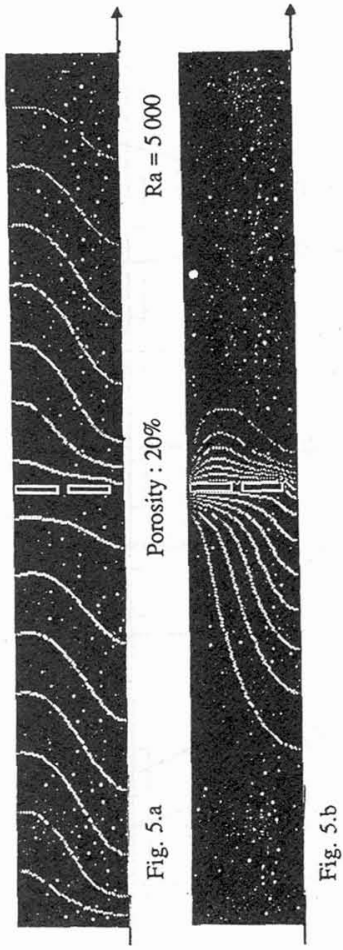

(a) linear temperature distributions; (b) thermosiphon

Fig.4 Streamlines

Fig.5 Isotherms 

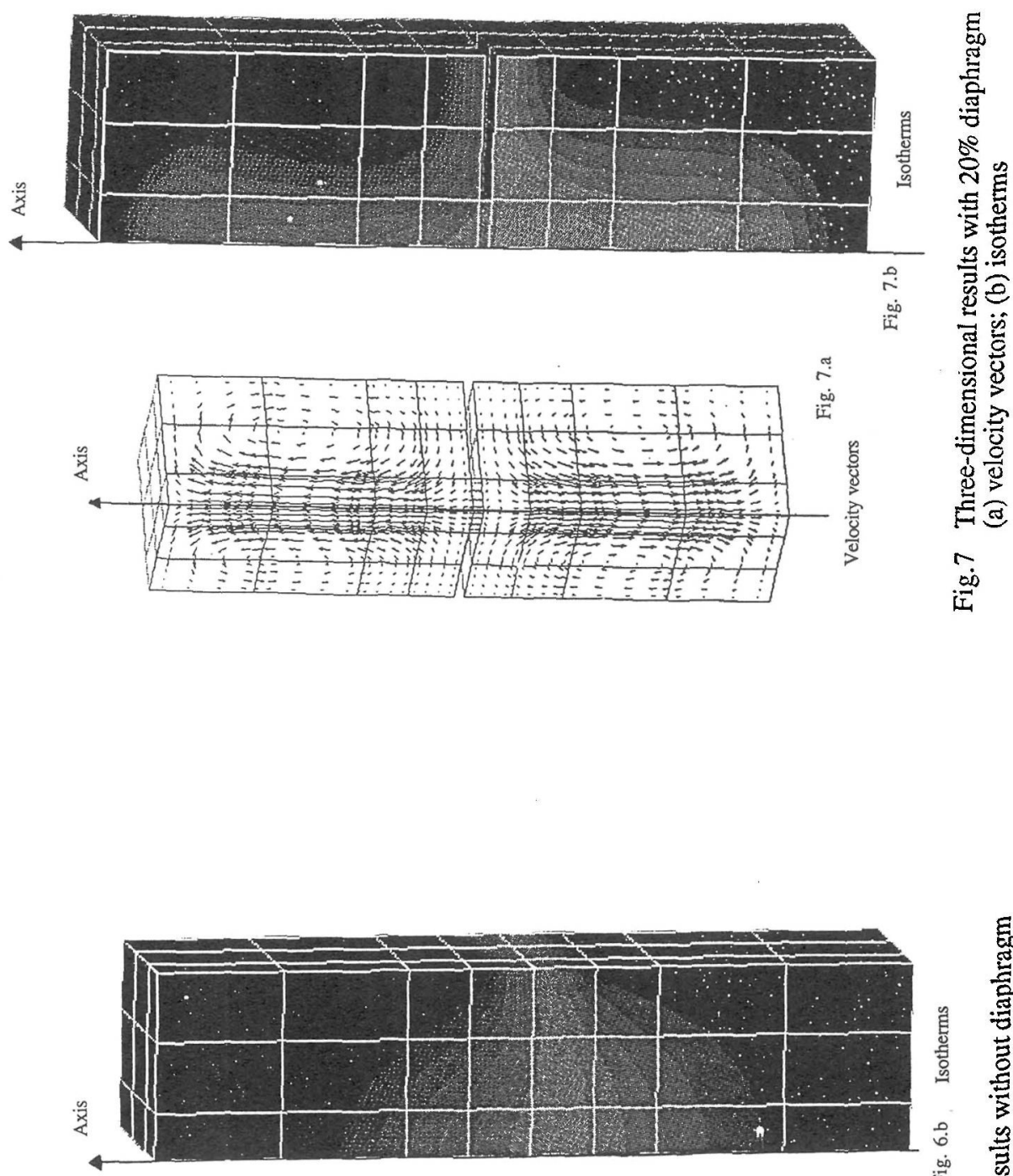

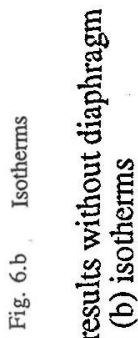

퐁

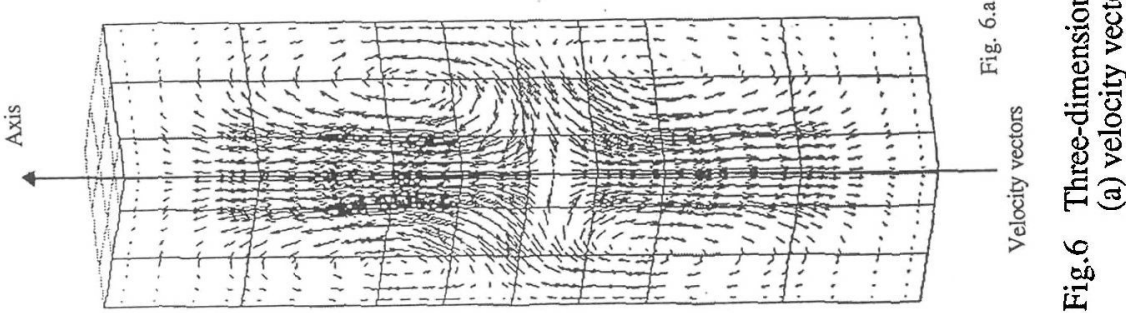

